\title{
Discursos de gênero e saúde: Debatendo a PNAISH com seus usuários
}

\author{
Jhonatan J. Miranda*, Thalita Rodrigues, Alberto Mesaque Martins, Mateus Aparecido Faria, \\ Douglas Marcos Pereira, Priscila Neves Silva, \& Celina Maria Modena \\ Universidade Federal de Minas Gerais, Belo Horizonte, MG, Brasil.
}

\begin{abstract}
RESUMO - Este trabalho visa confrontar o corpo instituído pela PNAISH com os corpos performatizados pelos usuários dessa política na Atenção Primária à Saúde (APS) de Belo Horizonte. Através da Análise do Discurso e da teoria da performatividade de gênero, analisou-se o corpus proveniente de entrevistas com 09 homens que utilizam os serviços da APS. Os resultados evidenciam, tanto performances de gênero que, consonantes com a PNAISH, se pautam no corpo genitalizado como forma de resistência ao cuidado; quanto performances de gênero que transgridem as perspectivas desta Política. Procurou-se fomentar as discussões sobre as dificuldades de integração de homens às políticas de saúde.
\end{abstract}

PALAVRAS-CHAVE: gênero, homens, análise do discurso, Sistema Único de Saúde

\section{Gender and health discourses: Debating PNAISH with users}

\begin{abstract}
The objective of this study was to confront man's body as conceptualized by PNAISH with man's body performatized by male users of this policy in Basic Health Care (BHC) in Belo Horizonte. Using speech analysis and the theory of gender perfomativity, the corpus derived of the interviews with 9 men who use the BHC services was analyzed. The results highlighted gender performance which, consistent with PNAISH, is based on a genitalized body as a way of care resistance, as well as gender performance that transgress the perspectives of this policy. This study sought to encourage discussions about difficulties of men's integration to health policies.

KEYWORDS: gender, men, speech analysis, unified health system
\end{abstract}

As iniciativas governamentais em saúde direcionadas para homens e mulheres, tanto no Brasil como em outros países, estão relacionadas a um contexto mais geral de aplicação do conceito de gênero na saúde. O feminismo foi o grande protagonista desse movimento ao problematizar as desigualdades históricas a partir do conceito de gênero na saúde e, também, pautar demandas para mulheres (Medrado \& Lyra, 2008; Medrado, Lyra, \& Azevedo, 2011; Schraiber \& Figueiredo, 2011). Em 2004, formulou-se a Política Nacional de Atenção Integral à Saúde da Mulher (PNAISM; Brasil, 2004), embora, na década de 1980, já se observassem iniciativas governamentais direcionadas à saúde da mulher em âmbito nacional (Brasil, 1985).

Os primeiros apontamentos para a necessidade de se dar importância à saúde dos homens surgem a partir da concepção do caráter relacional de gênero e compreendem que os déficits em saúde geram impactos negativos na saúde da mulher (Aquino, 2006; Medrado et al., 2011), tais como a violência doméstica, HIV/Aids, entre outros. Atualmente, defende-se que as ações em saúde dos homens não sejam, nem compreendidas secundariamente à saúde da mulher, nem esvaziadas do caráter relacional do conceito de gênero (Medrado et al., 2011). Conforme alerta Aquino (2006), não se deve retirar da categoria gênero seu potencial explicativo de princípio organizador da dinâmica social para tomá-lo simplesmente enquanto categoria empírica "politicamente correta". O que se verificou, a partir da década de 1990, foi que, durante muito tempo, houve predominância de uma produção científica sob uma perspectiva essencialista dos homens, predeterminados biologicamente e como se fossem todos iguais (Schraiber, Gomes \& Couto, 2005).

É nesse contexto histórico de disputa intelectual e política em torno do conceito de gênero, que foi formulada a Política Nacional de Atenção Integral à Saúde do Homem (PNAISH; Brasil, 2008), visando "promover a melhoria das condições de saúde da população masculina"

*E-mail: mirandajjhonatan@gmail.com 
(p.38). Em um estudo que analisa o discurso da PNAISH, Martins e Malamut (2013) apontam que a construção dessa política foi realizada através de figuras políticas pessoalizadas e do convite de equipe técnica imbuída de premissas biomédicas, sem a participação de cidadãos/ usuários dos serviços de saúde, bem como de movimentos sociais e outros atores políticos que se dedicam aos temas saúde e gênero. É também nessa direção que se entende a mobilização da Sociedade Brasileira de Urologia (SBU) junto a setores governamentais e o encontro de seus interesses com a criação de uma política pública de saúde para homens (Carrara, Russo \& Faro, 2009). Dessa forma, a institucionalização da PNAISH ocorre mais em função de decisão político-institucional, de caráter marcadamente biomédico, do que de demanda reconhecida e compartilhada pelo público que pretende representar (Martins \& Malamut, 2013).

Nesse sentido, muitos autores (Martins \& Malamut, 2013; Medrado et al., 2011; Müller, 2013, Schraiber \& Figueiredo, 2011) evidenciam a ênfase dada pela PNAISH ao trato de um corpo de homem que se define pelo sistema urogenital. É curioso notar a proximidade desse sujeito anatomopatológico ao qual a política se refere com o que Aquino (2005) advertiu, três anos antes do lançamento da PNAISH, acerca dos perigos da saúde do homem seguir o mesmo caminho de medicalização da sexualidade que a saúde da mulher experienciou.

Como afirma Müller (2008), "ao objetivar-se em uma cadeia, o discurso do SUS movimenta-se e faz existir sujeitos; institui e nomeia os sujeitos inteligíveis em saúde; dá corpo e consistência ao seu próprio discurso" (p.51). Essa concepção discursiva sobre a PNAISH encontra-se em consonância com Butler (2006):

Então, um discurso de gênero restritivo que insista no binário do homem e da mulher como forma exclusiva para compreensão do campo de gênero performa uma operação reguladora de poder que naturaliza o caso hegemônico e reduz a possibilidade de pensar em sua alteração (pp.70-71, tradução nossa).

O discurso da política, ao conceber gênero enquanto corpo biológico-reprodutor, relança-o para a dinâmica das relações de gênero na saúde, a partir de uma suposta coerência sexo-gênero-desejo (Butler, 2013). Cria, portanto, um sujeito intrincado ao binarismo homem-mulher, que restringe, por sua vez, a complexidade das masculinidades e os modos como se articulam com os discursos de saúde.

Segundo Butler (2001), as normas de gênero são regras discursivas que criam subjetividades a elas assujeitadas, através do reconhecimento e da diferenciação da reiteração contínua das normas. Nessa perspectiva, a forma como as masculinidades se distribuem hierarquicamente entre si e por oposição às feminilidades compreende diferentes performatizações das normas de gênero.

Butler (2013) problematiza que as dimensões sexo, gênero e desejo não são necessariamente interligadas, mas há um esforço constante das normas de gênero em estabelecer uma coerência e correlação. A reiteração do binarismo homem-mulher - seja no plano dos relacionamentos interpessoais, seja no plano discursivo institucional -, procura atualizar a coerência sexo-gênero-desejo, tomando o sexo como um atributo pré-discursivo, como também vinculando-o à heterossexualidade normativa.

A desnaturalização do sexo é um ponto fundamental da compreensão da teoria da performatividade de gênero. Não é apenas o gênero que é formado a partir de discursos sociais. Os corpos, as manifestações da sexualidade e as práticas sexuais também são recobertos de discursos cultural e historicamente datados (Butler, 2006, 2013; Foucault, 1980). Segundo a autora: "o gênero é a estilização repetida do corpo, um conjunto de atos repetidos no interior de uma estrutura reguladora altamente rígida, a qual se cristaliza no tempo para produzir a aparência de uma substância, de uma classe natural de ser" (Butler, 2013, p.59).

Tendo em vista que a PNAISH produz um sujeito "homem" reduzido a um aparato anatomopatológico, pergunta-se: como o corpo se faz presente na fala dos usuários dessa política pública, quando são inquiridos a respeito de saúde e gênero? Quais estratégias discursivas estão em jogo na performatização de gênero empreendida por esses usuários e o que elas podem levantar de ponto ou contraponto à PNAISH? Objetiva-se, com este trabalho, confrontar o corpo instituído pela PNAISH sobre seu sujeito, com os corpos marcados pelas performances de gênero dos usuários dessa política. Procura-se, ainda, fomentar as discussões sobre as dificuldades de integração de homens às políticas de saúde.

\section{MÉTODO}

O presente estudo se debruça sobre a linguagem enquanto meio de atualização e produção histórico-social de sentidos. Como método de abordagem, utilizou-se a análise do discurso em sua fundamentação francesa (Brandão, 2004; Orlandi, 2001).

Segundo Orlandi (2001), a análise do discurso pressupõe compreender o texto, não como transmissão de conteúdos e informações, mas como um complexo processo de constituição de sujeitos e produção de sentidos. Para essa autora, os dizeres são efeitos de sentidos produzidos em um contexto sócio-histórico determinado, o qual se faz presente de alguma forma no modo como se diz. Elementos desse contexto deixam vestígios que o analista de discurso tem de apreender, "pondo em relação o dizer com sua exterioridade, 
suas condições de produção" (p.30). Sob essa perspectiva, o enunciador não é mais a fonte do discurso. Formas discursivas se instalam, de modo a determinar aquilo que pode e deve ser dito, e é assujeitando-se a isso, ou seja, na maneira como emprega as palavras, que o indivíduo se faz sujeito do discurso.

A perspectiva butleriana segue a mesma direção teóricometodológica acima apresentada. Conforme explicitado anteriormente, para Butler (2001), as relações de gênero são dinâmicas discursivas responsáveis pelos processos de subjetivação, enquanto normas sociais, constituídas por e a partir de relações de poder. Essas normas antecedem a existência dos indivíduos, sendo atualizadas por eles discursivamente. $\mathrm{O}$ assujeitamento às normas de gênero demanda posicionamentos discursivos constantes ou, à maneira de Butler, performatizações, as quais podem ser analisadas para que se evidencie as diversas maneiras de atuação das normas.

\section{PROCEDIMENTOS E PARTICIPANTES}

Participaram do estudo 09 homens que utilizam os serviços da Atenção Primária à Saúde (APS) do município de Belo Horizonte (MG). O contexto da pesquisa foi escolhido, considerando-se o mapeamento de ações voltadas à saúde dos homens, realizado anteriormente por Martins e Modena (2016). Nesse sentido, o estudo foi realizado junto a 04 Unidades Básicas de Saúde (UBS) que já haviam realizado algum tipo de ação voltada para a população masculina. Para a escolha dos participantes, foi solicitado aos Agentes Comunitários de Saúde (ACS) da Estratégia Saúde da Família (ESF) de quatro UBS de Belo Horizonte que realizassem a busca e indicação de contatos para entrevistas. A opção de haver a intermediação para o levantamento dos contatos, através desses trabalhadores da saúde, tem relevância metodológica.

Segundo Araújo e Assunção (2004), os ACS constituem importante elo de vinculação entre serviços de saúde, políticas públicas de saúde e população, atuando na prevenção de doenças e na promoção da saúde. Esses autores salientam ainda as funções de mobilização e de desenvolvimento de habilidades de autocuidado, tão caras aos objetivos da PNAISH. O lugar institucional dos ACS na implementação das políticas, no âmbito da Atenção Básica, é de fundamental importância. Tal escolha metodológica para a seleção dos entrevistados objetivou reunir um grupo de usuários que refletisse a atual forma como essa política e seu público são compreendidos no âmbito da APS de Belo Horizonte.
A orientação fornecida aos ACS para o recolhimento de contatos foi a de que se tratava de uma entrevista sobre saúde do homem, a ser realizada com usuários na faixa etária entre 20 e 59 anos (idade delimitada pela própria PNAISH), moradores de seus territórios de abrangência. Dessa maneira, os entrevistados foram selecionados pelos ACS, dentro de seus processos rotineiros de trabalho e a partir de suas perspectivas de gênero e daquilo que entendem como público da PNAISH, tendo como base as delimitações feitas na orientação.

As entrevistas foram realizadas em horário e local escolhidos pelos próprios entrevistados e dirigidas por um roteiro semiestruturado, composto por três eixos temáticos: Condições e práticas de saúde, Gênero e saúde e Relação do entrevistado com a UBS de referência. O corpus analisado neste trabalho foi composto a partir da transcrição de nove entrevistas e anotações acerca do contexto enunciativo em que as entrevistas foram realizadas. A delimitação do corpus segue a presença dos discursos sobre gênero e saúde.

Em cumprimento da Resolução n ${ }^{\circ}$ 466/2012 do Conselho Nacional de Saúde, o projeto de pesquisa foi submetido ao Comitê de Ética em Pesquisas com Seres Humanos do CPqRR/Fiocruz Minas, sendo aprovado mediante parecer 28/2010. O projeto foi também aprovado pelo Comitê de Ética em Pesquisas da Prefeitura de Belo Horizonte (Parecer 0003.0.245.410-11A).

Tabela 1

Descrição de entrevistados por idade e ocupação.

\begin{tabular}{ccc}
\hline Usuário & Idade & Ocupação \\
\hline Entrevistado 1 & 45 anos & Dono de topa-tudo de ferro-velho \\
Entrevistado 2 & 59 anos & Torneiro mecânico aposentado/desempregado \\
Entrevistado 3 & 53 anos & Analista de sistema desempregado \\
Entrevistado 4 & 44 anos & Segurança e metalúrgico \\
Entrevistado 5 & 49 anos & Aposentado por invalidez \\
Entrevistado 6 & 36 anos & Dono e atendente de mercearia \\
Entrevistado 7 & 30 anos & Pedreiro \\
Entrevistado 8 & 38 anos & Desempregado \\
Entrevistado 9 & 37 anos & Guarda municipal \\
\hline
\end{tabular}




\section{RESULTADOS E DISCUSSÕES}

\section{Corpos Silenciados}

Nas conversas por telefone que tinham o objetivo de efetuar a marcação de horário das entrevistas, muitos indivíduos relataram indisponibilidade de tempo para as mesmas. Alguns afirmaram não possuir interesse para tal, e a maioria se mostrou desconfiada em relação ao conteúdo da entrevista. Dos usuários que aceitaram marcar horário e local para as entrevistas, muitos esqueceram e remarcaram, ou não compareceram conforme o combinado, bem como deixaram de atender às ligações da equipe.

Considera-se, sem dúvida, o total direito à recusa, por parte dos usuários, a se submeterem às entrevistas. Vale ressaltar, também, que a quantidade de variáveis envolvidas nessa triangulação usuários-UBS-equipe de pesquisa, bem como os próprios afazeres cotidianos dos usuários, vão além do que se poderia ler enquanto discursos de saúde e gênero. No entanto, pode-se afirmar que tais discursos se fazem presentes na medida em que os elementos contextuais envolvidos na forma como ficaram sabendo da entrevista evocam a relação homem-saúde e, assim, a resposta recebida dos usuários se vincula também a esses discursos. Dessa forma, o que se pode ler disso que se faz texto nesse momento inicial é a ausência, elemento tão apontado por diversos estudos no que diz respeito à saúde dos homens (Gomes et al., 2011).

Ao adentrar nas respostas, durante a primeira parte da entrevista, percebe-se que, ao ser questionado sobre seu estado de saúde, o Entrevistado 1 repete que sua "saúde está boa", "não sinto mal, nada não", "saúde de ferro". O entrevistado sustenta, inicialmente, que o único possível problema de saúde seria uma dor nas costas: "De uns tempos pra cá que tá começando a dar dor nas costas. Acho que éo trânsito, né? Chega a tarde, dá uma dor aqui, menino, fico caçando cama para descansar". Com o desenvolvimento da entrevista, é notável a mudança, surgindo em sua fala outros elementos inicialmente ocultados: uma frequente desarticulação de ombros que exige intervenção médica, cirurgias de apêndice e de hérnia umbilical, a diabetes descontrolada, o fumar compulsivo, o vício pelo álcool, sendo que esse último gera problemas intrafamiliares.

Enquanto há a preponderância significativa do enunciado "saúde de ferro", o sentido que acompanha os vícios, e suas consequentes implicações familiares e corporais, não emerge por completo. Porém, ele vai se inscrevendo na fala, a partir de modulações, como no uso do diminutivo em "gosto de tomar uma skolzinha" e na delimitação do hábito de fumar em "fumo quando tô bebendo, só". Já em "às vezes na sexta-feira vai no bo[teco], no bar beber uma cerveja", através da colocação do sujeito na terceira pessoa e a supressão da palavra "boteco" e sua correção por "bar", percebe-se uma modificação feita no processo da fala que evidencia a interferência ou disputa de sentidos.

Essa modulação dos sentidos, ao longo da entrevista, revela um conjunto de estratégias iniciais que correspondem à antecipação. $\mathrm{O}$ enunciador "antecipa-se assim a seu interlocutor quanto ao sentido que suas palavras produzem" (Brandão, 2004, p.39). A modulação utiliza-se de apagamentos e homogeneizações discursivas (Brandão, 2004) para evitar o sentido que não deve ser dito: um corpo avesso às regras de cuidado em saúde.

As falas sobre o autocuidado, através da alimentação e de exercícios físicos, apresentam um movimento similar. $\mathrm{O}$ Entrevistado 4, por exemplo, descreve, em detalhes, como a boa alimentação deve ser e diz:

Hoje você ta novo, aí vai passando, vai passando a idade e você começa 'ah... porque eu comi muito doce, hoje eu não posso comer, tenho que regular'. Então você mesmo vai se limitando. Eu acho que... e assim eu faço com a minha filha pra não fazer isso.

Várias são as regras de boa alimentação que esse entrevistado apresenta, as quais são aplicáveis à filha de dois anos e às discussões com a esposa, mas não a si próprio. Em outro momento, ele conta que faz apenas uma refeição ao longo de todo o dia e cobre o restante das horas com café, recriminando-se. Faz valer, dessa forma, o "pra não fazer isso" que a atitude de regramento da alimentação da filha propicia, ou seja, esse saber se aplica sobre o outro e não sobre si mesmo.

Outros quatro Entrevistados (4, 6, 8 e 9) reconhecem o cuidado através de exercícios físicos, como uma prática de saúde, embora nenhum deles os coloque em prática. $\mathrm{O}$ Entrevistado 9, por exemplo, já tendo deixado claro o lugar central da aparência física cultivada pelos exercícios, em seu entendimento sobre saúde, conta: "Deveria ter cuidado mais é mais na questão de atividade física, né? Porque os médicos tudo orienta pra 'você tem que fazer mais atividade fisica. Você tá engordando. Não sei o quê..."”. O entrevistador pergunta: "E o que te impede de fazer isso?". Sua resposta é: "Hoje, eu poderia falar que é preguiça. Só, mesmo [ri]. Porque é só medo de querer, de começar, né?".

Assim, entende-se que o imperativo do cuidado com o corpo, como obrigação individualizada, se faz presente no material analisado enquanto censura ou incongruência gerada por um "falo, mas não faço", estando a experiência corporal, por vezes, apartada da fala.

Outro silêncio que ocorre nas entrevistas diz respeito não apenas aos corpos que se ocultam, mas ao que mais radicalmente não pode ser falado. Corpos frágeis e vulneráveis são substituídos por enunciados como "nunca senti nada" (Entrevistado 2). Um ponto de tensão a esse 
respeito, na fala do Entrevistado 2, é quando se pergunta sobre quais riscos de saúde ele antevê em seu futuro, sendo esta sua resposta: "Na minha familia toda, a maioria do.... os filhos e minha mãe mesmo, são dezessete irmãos, hoje mantiveram quatro. Todos morreram dessa doença que eu não gosto nem de falar o nome, câncer". Após dizer isso, o entrevistado não diz mais a palavra "câncer" e passa a se referir a ela por "doença ruim". A impossibilidade da nomeação de uma doença tão fatal em sua história familiar deixa evidente a inconsistência do enunciado "nunca senti nada", uma vez que a própria menção da doença coloca em risco sua saúde, implicando, ao mesmo tempo, a emergência do sentido de um corpo que sente.

A primeira pessoa do singular se impõe quando as falas dizem respeito à intromissão de saberes sobre o corpo, sendo dessa forma que o Entrevistado 1 responde ao entrevistador a respeito da diabetes. Após sua cirurgia de apêndice e hérnia umbilical, os exames de glicose deram resultados alarmantes:

Entrevistado 1: Depois da cirurgia começou a subir. Entrevistador: Ah tá, ai então eles descobriram [a diabetes].

Entrevistado 1: Não, eu descobri.

O entrevistado rejeita os exames enquanto possibilidade de conhecimento sobre si mesmo e articula o diagnóstico apenas com suas próprias impressões do corpo.

O Entrevistado 4 diz algo parecido:

Antes de eu ir pra lá [refere-se ao período em que morou em outro país] eu bebia. Vi que tava me prejudicando, parei. Ai fumava, vi que não dava certo, parei também. Tudo na vida da gente, a gente tem uma opinião, né? Se não tiver uma opinião...

Nessa fala, o enunciador aloca o consumo de bebidas alcoólicas e de cigarros como hábitos controláveis por sua opinião, pelo próprio julgamento variável que o permite em um momento beber e fumar e, em outro, interromper tais hábitos, deliberadamente. Nas falas apresentadas, nota-se a localização dos enunciadores como protagonistas dos saberes e ações que dizem sobre seus corpos.

A riqueza polissêmica própria das metáforas auxilia na apreensão do protagonismo identificado. Narrando a maneira como cuida de seu corpo e de sua saúde, diz o Entrevistado 1: "Se tomar cerveja, comer um tira-gosto forte, uma feijoada, pé de porco, ai ela [glicose] dá uma aumentada. Vai pra 200 e tanto. Ai eu tiro o pé, paro de beber uma semana ou duas, ai controla". A expressão "tiro o pé", como forma de controle do vai e vem alimentar, sugere que o enunciador, ao falar de sua saúde, coloca-se enquanto indivíduo capaz de dosar as acelerações que impõe a seu corpo, como um motorista de si mesmo. O sentido se repete: "Controlo e está tudo bem".
Analisando as entrevistas, vê-se que conflitos aparecem na busca desses indivíduos pelos serviços de saúde, uma vez que os saberes especialistas biomédicos surgem como interferências para o posicionamento autodominante sobre o próprio corpo. Nos serviços de saúde, é o outro que toma a voz sobre si, impedindo os indivíduos (ou sujeitos) de se enunciarem.

Tais análises continuam circunscrevendo os enunciados no campo do biopoder, na medida em que se percebe a utilização de discursos de verdades sobre o corpo, produtores da responsabilização individual pelo cuidado, em nome da vida e saúde de coletividades (Rabinow \& Rose, 2006). Porém, à realização discursiva do biopoder, sobrepõe-se o posicionamento sobre as relações de gênero: uns falam e outros são falados (Mosse, 1996). Entende-se aqui que a ramificação do poder sobre a vida, que incide individualmente e domina os corpos, faz diferentes articulações com os discursos de gênero. A presença do protagonismo no discurso sobre saúde, embora seja algo que se vincule ao biopoder, também se relaciona com as subjetividades produzidas a partir de normas de gênero: ser homem está, histórica e socialmente, marcado pelo imperativo de falar sobre a vida pública, sobre a família "ter opinião", tal como nomeia o Entrevistado 4 -, normas reconhecidas, como constituidoras de subjetividades masculinas e performatizadas nas falas analisadas.

Segundo Foucault (1995), "não há relação de poder sem resistência" (p.248), ou seja, toda relação produz oposições, distorções, produções variadas do poder. $\mathrm{Na}$ análise em questão, o corpo é alvo da disputa entre o biopoder, com seus dispositivos biomédicos de controle dos corpos, e as normas binárias de gênero, produtoras de relações de domínio. Desse conflito, advém a série de censuras, mutismos, silenciamentos e apropriações de corpos femininos enunciadas pelos entrevistados. A resistência à colonização do corpo pelo saber do outro encontra sua linha de fuga através das normas de gênero.

\section{Trabalho e Binarismo de Gênero: Corpos Falados}

Estudos sobre saúde masculina têm sinalizado elementos analíticos para a compreensão do distanciamento entre a atenção primária à saúde e o público-alvo da PNAISH. Um desses elementos tem sido a compreensão de que homens são provedores de suas famílias, trabalham fora e que não teriam a disponibilidade de irem às UBS em horário comercial (Figueiredo \& Schraiber, 2011; Gomes et al., 2011). Se articulações entre trabalho e masculinidades forem explicadas a partir de ideias como "imaginário social", pode-se contribuir com a fixidez do binarismo de gênero, segundo o qual aos homens caberia a responsabilidade de sustento da família e, às mulheres, o cuidado doméstico da casa, dos filhos e do companheiro. Noções como essas implicariam em uma definição prévia de papéis sociais que 
podem tanto reificar discursos e subjetividades, quanto podem não se atentar às nuances que as próprias categorias homens e mulheres detêm.

Uma compreensão binária sobre a ausência dos homens na atenção primária poderia levar à explicação de que isso se dá apenas devido ao trabalho formal em horário comercial, ao passo que as mulheres têm sido produzidas enquanto sujeitos do cuidado e os homens não. Posições extremadas sobre homens e saúde abrem margem para posturas de culpabilização dos homens, por não procurarem os serviços de saúde e não se cuidarem. Tal perspectiva trata o distanciamento ou silenciamento como trabalhado no tópico anterior, como se fosse algo inerente e exclusivo dos homens e não se relacionasse com dinâmicas sociais amplas que são atualizadas cotidianamente por todos. Outra postura poderia ser a de vitimização, considerando esse grupo apenas como vítimas das relações de gênero e saúde. Desconsiderar-se-iam, dessa maneira, seus privilégios nas relações sociais, simplificando a complexidade da interação entre dinâmicas sociais e as subjetivações generificadas.

Tais aspectos devem ser debatidos a partir de uma compreensão de gênero enquanto categoria radicalmente relacional, em que tais fenômenos sociais se fundam em processos dinâmicos de dominação entre os corpos, algo que se dá no fazer discursivo. Dessa forma, pode-se apreendê-los no modo como os sujeitos se fazem na fala.

De acordo com Nogueira (2001), os estudos sobre as relações de gênero em psicologia têm sido compreendidos em duas principais correntes: as empiricistas e as pósmodernas, sendo que as perspectivas empiricistas se subdividiriam em essencialistas e da socialização. Em ambas as perspectivas, haveria a essencialização das diferenças: "Os modelos essencialistas concebem o gênero em termos de atributos fundamentais, concebidos como internos, persistentes" (Nogueira, 2001, p. 140). Portanto, a análise de Nogueira (2001) deve servir de alerta para que não apenas as práticas de intervenção em saúde do homem, mas também as pesquisas e estudos se atentem às dicotomizações e binarismos de gênero, a fim de não reproduzirem análises também dicotômicas e essencialistas.

O Entrevistado 1 traz essa perspectiva binária de gênero para justificar seu afastamento dos serviços e das práticas de saúde. Como ele aponta: "Não para não, é a vida. Essa correria aí não tem jeito de parar, não. Ela não trabalha, minha esposa é dona do lar, os meninos estão pequenos ainda". O entrevistado não atribui à "dona do lar" o status de trabalho e expressa a expectativa dos filhos trabalharem para que não seja mais o único responsável pelo sustento financeiro da família, embora não inclua, novamente, a esposa nessas expectativas.

É importante evidenciar como a exigência de ser o responsável pelo sustento familiar incide como uma obrigação, à qual o entrevistado e, futuramente, seus filhos - "dois homens", como salienta - devem corresponder.
Esse discurso, que é atualizado pelo Entrevistado 1 - e que, por conseguinte, antecede a sua fala -, performatiza, no dizer, dinâmicas sociais que se baseiam em binarismos e dicotomias sobre o que pode vir a ser homem e mulher. Através de interlocutores imaginários, sendo aqui apresentados através do discurso médico, o entrevistado atualiza o que é cotidiana e exaustivamente propagado em diversos espaços sociais: "O negócio é sério. Ela [médica] falou: 'Oh, você toma o remédio direito, você tem menino pequeno ainda, você... tudo depende de você, então você tem que controlar'"' (Entrevistado 1).

$\mathrm{Na}$ fala desse enunciador imaginário, percebe-se a carga de responsabilidade atribuída ao entrevistado pela frequência da palavra "você". A dimensão relacional e performativa das relações de gênero auxilia a compreensão de que não são apenas os próprios homens que incorporam e reproduzem o discurso de "homens provedores". Outros interlocutores, e mesmo outras instituições, reforçam essa máxima. A utilização do enunciador imaginário remonta, no dizer, a uma memória discursiva, a qual, nesse caso, refere-se à localização generificada dos membros da família e à (auto) responsabilização de um desses (o homem) por seu sustento. É fundamental destacar que a (auto)atribuição da posição de provedor ao homem se sustenta numa lógica de "controle", aspecto esse que remonta a dinâmica dos gêneros em que há corpos, os masculinos, que se fazem sujeitos a partir do controle de si e de outros corpos.

$\mathrm{O}$ argumento do homem provedor, aliado ao binarismo de gênero, tem efeito discursivo: O corpo produtivo, capaz, naturalmente forte, é tomado enquanto ideal masculino. No entanto, no material analisado, percebe-se que, quando o discurso do trabalho se faz presente, esse corpo pode apresentar avarias. O Entrevistado 2, por exemplo, conta:

Tem um problema que eu passei, que eu mexia com
transporte de som, transportava caixa de som muito
pesadas. Ai o reto saiu fora. Quase morri com
aquilo. E o médico tentou colocar pra dentro, mas
não conseguia. Ai me mandaram lá pro [menciona
o nome da UPA]. Aí conseguiram colocar lá. Mas
sofri... fora isso, nada, nada, nada. Foi por causa do
peso, as caixas são muito pesadas e... aconteceu isso,
mas aí ficou tudo bem.

Já o Entrevistado 3 inicia sua apresentação dizendo ter "uma vida mais ativa, né?". Explica que deixou seu trabalho de analista de sistemas em multinacionais e, atualmente, desenvolve oficinas com sua esposa em escolas. Sobre o trabalho de analista de sistema, ele relata:

É uma área que vai desgastando porque é muito acelerado, né? E quanto a projetos é tudo assim, tudo é pra ontem... os projetos são sempre pra ontem, a cobrança é sempre muito violenta. Então você segura muito tempo, né? Depois também... desgasta bastante. (Entrevistado 3) 
A utilização da fala de um profissional da saúde que o acompanhou durante 15 anos, fornece a autoridade necessária para atestar o sentido de sobrecarga de trabalho: "ele mesmo [médico] me acompanhava, ele brincava muito, falava isso: 'É, sô, esse trabalho te consome bastante'. Eu senti sobrecarga".

Curiosamente, as qualificações de trabalho presentes nas falas acima (ser pesado, desgastar, sobrecarregar e ser excessivo) são enunciadas apenas como consequências do trabalho e não aparecem articuladas às falas de saúde e cuidado. As normas, formadoras de subjetividades que modelam corpos para o trabalho, modificam o sentido dos efeitos destrutivos e fragilizadores do trabalho sobre os corpos, tornando tais efeitos positivos, compreensíveis e reiteradores de um sujeito trabalhador. Tais efeitos não seriam reconhecidos com o sentido de falha, fragilidade ou de demanda de cuidado, mas, ao contrário, parecem reforçar a ideia do sujeito capaz de prover. Assim, não confrontando as relações de gênero com saúde, corpos "avariados" pelo trabalho puderam ser falados.

\section{Corpos a Serem Providos:A Estratégia Biologizante}

Na lógica binária de gênero, o homem provedor, cujo ideal de corpo é construído como potência produtiva, encontra um corpo feminino como seu contraponto sustentador, aquele que é provido. No tocante à saúde, percebe-se que "prover" e "ser provido" possuem equivalentes significativos e que os corpos são ditos penetráveis e não-penetráveis: " $A h, a$ mulher tem mais problema, né? Infecção de urina ...sempre ta tendo penetração, aí vai o homem, ai tem infecção de urina, a mulher tem mais problema. Eu não sei explicar direito não [diz rindo]. Mulher previne mais" (Entrevistado 1).

Um corpo feminino marcado pela suposta penetrabilidade natural faz a oposição entre cuidado e não-cuidado, como esse entrevistado arrisca dizer ao procurar explicações para a diferença de acesso entre homens e mulheres aos serviços de saúde. O discurso de naturalização da diferença sexual, que constrói a categoria mulher a partir do imaginário em torno de um corpo que precisa de complementos, incide tanto na sustentação do "homem provedor", quanto no cuidado em saúde como algo próprio de mulheres.

A equivalência entre penetração e cuidado com o corpo denota a performatização de um corpo não penetrável pela recusa do cuidado. Nesse sentido, o Entrevistado 4 afirma:

O homem não toma nada, não. O homem é... ai tem uns vinte negócio de remédio... [indica com o dedo um móvel de sua casa. O entrevistado está fazendo referência ao modo como percebe que sua esposa cuida da saúde]. Tudo é 'ah, tô sentindo isso', toma isso, toma aquilo, toma não sei o quê lá. 'Ah, não sei quem falou que esse [remédio] aqui é bom'e toma. Os homens... eu já vi muitos homens que não tomam. Acha que não é necessário, né?
A fala desse entrevistado, que afirma não tomar remédios, evidencia a oposição entre um corpo feminino aberto para as sensações e pronto para tomar o que for lhe dado e homens fechados, autossuficientes. O Entrevistado 3 utiliza a mesma estratégia argumentativa de naturalização da diferença sexual:

A mulher, por ela já ter... ela vai no posto médico, por exemplo, vai fazer um exame, ai nisso ela tá percebendo que o olho dela tem um negocinho, ela já, de repente, ela já marca uma consulta. O homem, às vezes, ele não vai procurar o médico porque ele tem um... porque parece que tem um cisquinho aqui.

O uso do diminutivo em "negocinho" e "cisquinho" intensifica o sentido do enunciado de que a gravidade necessária para mulheres buscarem ajuda nos serviços de saúde é baixa. Um pouco mais adiante surge a justificativa naturalizante para essa diferenciação:

[A mulher] pode ter mais problemas porque ela tem útero, ela tem... por o sistema dela poder apresentar problemas, ela tem exame de mama que ela tem que fazer. Então eu acho que isso acaba levando ela mais. Acaba levando ela mais e... e às vezes por aí ela acaba procurando outras coisas também no posto médico. (Entrevistado 3)

Interessante notar que o uso da expressão "o sistema dela poder apresentar problemas" se conecta com a atividade profissional do enunciador (analista de sistemas), fazendo valer novamente o posicionamento de gênero a partir do trabalho. Na dinâmica dos gêneros, o corpo masculino é performatizado ao se colocar em contraste com o corpoproblema, de útero e seios, demandante de intervenções para sua complexidade, pronta para falhar. Desenha-se, performaticamente, um resistente corpo masculino, o corpo-pênis, que não requer cuidados em função de sua suposta simplicidade anatômica e fisiológica. Seguindo os caminhos dessa fala, percebe-se a hierarquização dos corpos explicitada na superfície do texto, possibilitada por um terceiro sujeito: "Talvez, talvez no intimo ta a visão errônea de que ele tem algum tipo de... qualquer coisa é 'ah, isso é bobagem'. É um certo tipo de... não sei se é a palavra adequada, né? Mas o homem pode se achar um pouco superior, né?" (Entrevistado 3).

Conforme a PNAISM afirma (Brasil, 2004), “a vulnerabilidade feminina frente a certas doenças e causas de morte está mais relacionada com a situação de discriminação na sociedade do que com fatores biológicos" (p .9). A utilização de gênero como categoria analítica a partir da perspectiva relacional coloca em discussão a importância de desconstruir as naturalizações que modelam discursos de gênero e sustentam mecanismos sociais adoecedores.

Desconstruir naturalizações possibilita a visualização e emergência de divergências e pluralidades na compreensão 
sobre corpos, relações de gênero e saúde. As falas de dois entrevistados permitiram identificar discrepâncias significativas em comparação ao que se apresentou até aqui como um conjunto quase homogêneo do corpus analisado. A partir dessas falas, é possível compreender movimentos performativos de deslocamentos da exigência normativa da coerência sexo-gênero-desejo das normas de gênero.

O Entrevistado 8 convida seu entrevistador, a todo o momento, a adentrar no hall de dores, doenças, anomalias, isolamento radical do meio social e toda a variedade de perturbações que vivencia. Sua fala é marcada pelas denúncias dos mais diversos tipos. Entre elas, está a inadequação na atenção primária, em função da heterodeclaração de como deve ser um homem:

Então, tipo assim, às vezes eles já te dá uma posição, assim, antes, sem medicamento, né? O problema todo é esse, né? Não é igual entre homem e mulher, igual eu te falei. 'Mulher tem isso'e 'a mulher é assim, é mais frágil', mas a gente que é homem, a gente chega [na UBS] e falam 'não, o cara tem um porte físico legal, tá bom'. E não acredita. Igual eu te falo, isso vem há tempos. (Entrevistado 8)

O propósito em destacar a fala acima não é o de simplesmente corroborar a denúncia que ela veicula, relacionada à dificuldade social, mesmo das instituições de saúde, em reconhecer corpos masculinos como adoecidos, frágeis (Faria et al., 2015). Busca-se apontar que, diferentemente do que foi apresentado na primeira parte das análises deste trabalho, as inter-relações entre os discursos de saúde e de gênero não se apresentam apenas como resistência ao discurso biomédico. Aqui, a dinâmica interdiscursiva ocorre de maneira inversa. A performatização de gênero não opera no sentido de se contrapor ao discurso biomédico, mas para denunciá-lo:

Eu sou muito crítico porque sei lá. Eu me excluo um pouco, eu me excluo totalmente da sociedade com relação ao homem, né? Porque hoje o cara vive pra trabalhar, né? ... Então, eu sou muito crítico com relação a isso: homem. O homem... o homem é machista, entendeu? A realidade é essa. Sei lá, eu acho que você tocou num assunto que eu passo a noite pensando. (Entrevistado 8)

Ao não se reconhecer e não ser reconhecido como homem saudável, dono de si e de seu corpo, que rejeita as fragilidades e "avarias" - pressuposto de estereótipos de gênero - o entrevistado se diz excluído, de fora. Isso porque nem o trabalho e nem um corpo biológico fornecem a base de sustentação para a performatização de gênero "esperada". Os longos trechos em que a sua fala se volta para descrições sobre os problemas com o próprio pênis não são maiores ou mais enfáticos do que os relativos às dores no coração, nos dentes ou na cabeça. Um corpo múltiplo de partes defeituosas - para além da ênfase urogenital - emerge como denúncia da impossibilidade de cuidado, não porque o próprio entrevistado o recusa, mas porque lhe é recusada a possibilidade de ser um corpo fragilizado e com demandas de saúde.

De maneira similar, as falas do Entrevistado 5 evidenciam um corpo-doença. A insuficiência cardíaca é a insígnia de apresentação do sujeito: "Meu nome é Entrevistado 5. Minha idade é 49 anos, sou aposentado por invalidez porque eu tenho insuficiência cardíaca e perda de $80 \%$ do lado esquerdo do coração". Tal insígnia percorre o texto interferindo e rearranjando as performatizações de gênero. Diferentemente do corpo-provedor presente nas demais entrevistas, aqui é um corpo-inválido que acompanha todas as evocações de trabalho. No entanto, também, divergindo da maneira como as falas do Entrevistado 8 produzem um sujeito que denuncia e busca se excluir, o corpo-inválido faz vínculos e circula, uma vez que pode ser bem capturado pelo discurso biomédico. É assim que são relatadas as entrevistas para emissoras de TV e os telefonemas pessoais de médicos, todos em função da sustentação de sua insígnia. Na mesma direção, diz sobre seu hospital de referência:

é lógico que ali você é uma cobaia, acaba sendo uma
cobaia, né? Mas se você mostra que tá tendo resultado
aquilo que eles fazem com você, eles adianta seu
lado: 'Tá adiantando o nosso, vamos adiantar o dele
também'. Eu consigo tudo ali... enquanto uma pessoa
leva, às vezes, 3 meses, com uma semana eu consigo!
Não é privilégio, não é privilégio que eu tenho. É, mas
é dedicação da gente. (Entrevistado 8)

A análise dessas últimas falas visa evidenciar performatizações que escapam da centralidade que o posicionamento de gênero pode ter ao percorrer os discursos de saúde. Não é apenas o corpo-pênis-provedor-impenetrável que interpela e demanda cuidados em saúde. Evidencia-se, portanto, os dissensos, transgressões que escapam de uma suposta homogeneidade dos posicionamentos de homens frente à própria saúde.

\section{CONSIDERAÇÕES FINAIS: SUJEITO DA PNAISH E AS PERFORMATIZAÇÕES DOS USUÁRIOS}

Ao ser formulada, a PNAISH se posiciona no contexto de tensão política em torno da categoria de gênero, privilegiando um discurso biomédico, no qual o corpo é reduzido ao sistema urogenital. Esse posicionamento repete o discurso social hegemônico, em que homens são compreendidos e se compreendem a partir das significações 
de um corpo-pênis. A articulação desse discurso com o discurso do cuidado em saúde, no que se pôde afirmar sobre uma parte significativa das análises das entrevistas com usuários, serve para silenciar, afastar e resistir às fragilidades que o âmbito do cuidado evoca. É paradoxal que se crie um sujeito para uma política pública em saúde do homem em que o posicionamento de gênero reitera as resistências de seus usuários para o cuidado em saúde.

Outra parte das análises permitiu ver deslocamentos performativos das normas de gênero que desestabilizam o sujeito da PNAISH. Nessas performatizações, outros corpos surgiram, os quais não se sustentam, nem a partir do trabalho, nem do aparelho urogenital, não estando contemplados pelo sujeito desta política e, portanto, pelos desdobramentos que esse sujeito prediz. É fundamental que a política pública, para utilizar gênero e especificar seu público direto, não se baseie em uma genitalização do corpo e compreenda "homem" de modo dinâmico, relacional e político - uma política que se instaura com hierarquias intra e extra grupo.
Percebendo uma explícita convergência da PNAISH, no que tange à redução da complexidade da categoria "homem" ao aparato urogenital, e as falas de muito entrevistados, pergunta-se: seria possível um trabalho mais abrangente da PNAISH de real inclusão dos homens, no plural? Tal trabalho seria possível sem ações conjuntas de reflexão sobre relações de gênero e impactos dos estereótipos e preconceitos no afastamento dos homens da atenção básica? Essas são questões reflexivas que não se esgotam. Os resultados da pesquisa evidenciam que é necessário que ocorra o que Aquino (2006) problematiza: a incorporação do conceito de gênero enquanto categoria de organização e análise social e não apenas como "uso politicamente correto". Para que isso ocorra, por sua vez, fazem-se necessárias estratégias de ruptura dos intricamentos dos discursos de gênero e biopoder, uma vez que seus efeitos estão comprometidos com a dinâmica de dominação entre os corpos que afasta homens do cuidado.

\section{REFERÊNCIAS}

Aquino, E. M. L. (2005). Saúde do homem: Uma nova etapa da medicalização da sexualidade? Ciência \& Saúde Coletiva, 10(1), 19-22.

Aquino, E. M. L. (2006). Gênero e saúde: Perfil e tendências da produção científica no Brasil. Revista de Saúde Pública, 40(esp.), 121-132.

Araújo, M. R. N., \& Assunção, R. S. (2004). A atuação do agente comunitário de saúde na promoção da saúde e na prevenção de doenças. Revista Brasileira de Enfermagem, 57(1), 19-25.

Brandão, H. H. (2004). Introdução à análise do discurso (2a ed. revisada). Campinas, SP: UNICAMP.

Brasil. Ministério da Saúde. (1985). Assistência integral à saúde da mulher: Bases de ação programática. Brasília: Centro de documentação do Ministério da Saúde.

Brasil. Ministério da Saúde. (2004). Política Nacional de Atenção Integral a Saúde da Mulher. Brasília: Ministério da Saúde.

Brasil. Ministério da Saúde. (2008). Política Nacional de Atenção Integral a Saúde do Homem. Brasília: Ministério da Saúde.

Butler, J. (2006). Deshacer el género. Barcelona: Paidós Ibérica.

Butler, J. (2001). Mecanismos psíquicos del poder: Teorías sobre la sujeción. Madri: Cátedra.

Butler, J. (2013). Problemas de gênero: Feminismo e subversão da identidade (Renato Aguiar, Trad., $5^{\text {a }}$. ed). Rio de Janeiro: Civilização Brasileira.

Carrara, S., Russo, J.A., \& Faro, L. (2009). A política de atenção à saúde do homem no Brasil. Physis: Revista de Saúde Coletiva, 19(3), 659-678.

Faria, M. A., Paula, D. M. P., Martins, A. M., Miranda, J .J., NevesSilva, P., Rodrigues, T., \& Modena, C. M. (2015). Política nacional de atenção integral à saúde do homem: Percepções de gestores de unidades básicas de saúde de Belo Horizonte-MG. Espaço para a Saúde, 16(3), 5-13.

Figueiredo, W. S., \& Schraiber, L. B. (2011). Concepções de gênero de homens usuários e profissionais de saúde de serviços de atenção primária e os possíveis impactos na saúde da população masculina, São Paulo, Brasil. Ciência \& Saúde Coletiva, 16(Suppl. 1), 935-944.

Foucault, M. (1980). História da Sexualidade I: A vontade de saber (M. T. da Costa \& J. A. Guilhon Albuquerque, Trad., $3^{\text {a }}$ Ed., pp. 231-249). Rio de Janeiro, RJ: Graal.

Foucault, M. (1995). O sujeito e o poder. In H. Dreyfus \& P. Rabinow, (Eds.), Michel Foucault: uma trajetória filosófica para além do estruturalismo e da hermenêutica. Rio de Janeiro: Fuorense Universitária.
Gomes, R., Moreira, M. C. N., Nascimento, E. F., Rebello, L. E. F. S., Couto, M. T., \& Schraiber, L. B. (2011). Os homens não vêm! Ausência e/ou invisibilidade masculina na atenção primária. Ciência \& Saúde Coletiva, 16(Suppl. 1), 983-992.

Martins, A. M., \& Malamut, B. S. (2013). Análise do discurso da Política Nacional de Atenção Integral à Saúde do Homem. Saúde e Sociedade, 22(2), 429-440.

Martins, A. M., \& Modena, C.M. (2016). Concepções sobre o cuidado e Saúde do Homem: A perspectiva de usuários e trabalhadores da Atenção Primária à Saúde. Belo Horizonte: Fiocruz Minas.

Medrado, B., \& Lyra, J. (2008). Por uma matriz feminista de gênero para os estudos sobre homens e masculinidades. Estudos Feministas, 16(3), 145-158.

Medrado, B.; Lyra, J., \& Azevedo, M. (2011). 'Eu não sou só próstata, eu sou um homem!' Por uma política pública de saúde transformadora da ordem de gênero. In R. Gomes (Org.), Saúde do homem em debate (pp.39-74). Rio de Janeiro, RJ: Fiocruz.

Mosse, G. L. (1996). The Image of Man: The creation of modern masculinity. New York: Oxford University Press.

Müller, R. F. (2008). Homens falados: performances de gênero e corpo nos paradoxos de serviços públicos de saúde (Unpublished master's thesis). Universidade Federal de Santa Catarina, Florianópolis, Santa Catarina, Brasil.

Müller, R. F. (2013). Violência, vulnerabilidade e risco na Política Nacional de Atenção Integral à Saúde do Homem. Revista EPOS, 4, 23-32.

Nogueira, C. (2001). Contribuições do construcionismo social a uma nova psicologia do gênero. Cadernos de Pesquisa, (112), 137-153.

Orlandi, E. P. (2001). Análise do discurso: Princípios e procedimentos ( $3^{\mathrm{a}}$ ed.). Campinas, SP: Pontes.

Rabinow, P., \& Rose, N. (2006). O conceito de biopoder hoje. Revista de Ciências Sociais, 24, 27-57.

Schraiber, L. B., \& Figueiredo, W. S. (2011). Integralidade em saúde e os homens na perspectiva relacional de gênero. In R. Gomes (Org.). Saúde do homem em debate (pp. 19-38). Rio de Janeiro, RJ: Fiocruz.

Schraiber, L. B., Gomes, R., \& Couto, M. T. (2005). Homens e saúde na pauta da Saúde Coletiva. Ciência \& Saúde Coletiva, 10(1), 7-17. 